\title{
Regional models of genetic services in the United States
}

\author{
Celia Kaye, MD, PhD ${ }^{1}$, Joann Bodurtha, MD, MPH ${ }^{2}{ }^{2}$, Mathew Edick, PhD ${ }^{3}$, Susanna Ginsburg, MSW ${ }^{1}$, \\ Alisha Keehn, MPA ${ }^{1}$, Michele Lloyd-Puryear, MD, PhD ${ }^{1}{ }^{1}$, Debra Lochner Doyle, MS, CGC ${ }^{4}$, \\ Megan Lyon, MPH (D) ${ }^{1}$, Robert Ostrander, MD ${ }^{5}$ and \\ Matthew Taylor, MD, PhD ${ }^{6}$, the National Coordinating Center for the Regional Genetic Service \\ Collaboratives Regional Support Service Model Workgroup and Advisory Committee
}

\begin{abstract}
Purpose: To outline structures for regional genetic services support centers that improve access to clinical genetic services.

Methods: A workgroup (WG) and advisory committee (AC) (1) conducted a comprehensive review of existing models for delivering health care through a regional infrastructure, especially for genetic conditions; (2) analyzed data from a needs assessment conducted by the National Coordinating Center (NCC) to determine important components of a regional genetic services support center; and (3) prioritized components of a regional genetic services support system.
\end{abstract}

Results: Analysis of identified priorities and existing regional systems led to development of eight models for regional genetic services support centers. A hybrid model was recommended that included an active role for patients and families, national data development and collection, promotion of efficient and quality genetic clinical practices, healthcare professional support for nongeneticists, and technical assistance to healthcare professionals.

Conclusion: Given the challenges in improving access to genetic services, especially for underserved populations, regional models for genetic services support centers offer an opportunity to improve access to genetic services to local populations. Although a regional model can facilitate access, some systemic issues exist-e.g., distribution of a workforce trained in genetics-that regional genetic services support centers cannot resolve.

Genetics in Medicine (2020) 22:381-388; https://doi.org/10.1038/s41436019-0648-1

Keywords: Public health; genetic services; regional models; access to service

\section{INTRODUCTION}

Increasing genetics and genomics knowledge of health-care professionals and the general population promises disease prevention, improved diagnosis, and innovative treatments of genetic conditions. However, limited access to genetic services for many individuals remains a problem (Alexander et al., 2015). In 2004, the Maternal and Child Health Bureau of the Health Resources and Services Administration (MCHB/ HRSA), Genetic Services Branch (GSB) awarded grants to establish seven Genetics and Newborn Screening Regional Collaborative Groups (RCs) and a National Coordinating Center (NCC) as part of efforts to improve the health of children and their families. Their goal is to promote the translation of genetic medicine into public health and healthcare services.

In 2015, the NCC began a process of assessing what models of regional genetic services support centers might help close gaps in access to genetic services. In addition, the process considered how future genetic services might be designed/ defined given the increased role of non-genetic service providers, the shifting healthcare environment within the United States, and future technological developments within the science of genetics and genomics. Primary care professionals and other specialists, rather than genetic services providers, will be expected to not only oversee the long-term management of a clinical condition, but also to understand the genetic risk factors underlying the condition and how genetics will affect treatment options for the individual patient. Movement toward implementing precision medicine paradigms will further introduce pressures to increase genetic considerations into practice models.

Identifying the structures required for the delivery of genetic services and the indicators of quality, effectiveness, and success of genetic services requires definition of the overall aims and elements of clinical genetic services. For the NCC assessment process, genetic services were divided into

\footnotetext{
${ }^{1}$ American College of Medical Genetics and Genomics, Bethesda, MD, USA; ${ }^{2}$ Johns Hopkins School of Medicine, McKusick-Nathans Institute of Genetic Medicine, Johns Hopkins University, Baltimore, MD, USA; ${ }^{3}$ Michigan Public Health Institute, Okemos, MI, USA; ${ }^{4}$ Washington State Department of Health, Kent, WA, USA; ${ }^{5}$ alley View Family Practice, Rushville, NY, USA; ${ }^{6}$ University of Colorado School of Medicine, Aurora, CO, USA. Correspondence: Alisha Keehn (akeehn@acmg.net) RSSM Workgroup members (http://www.nccrcg.org/RSSMWG); and RSSM Advisory Committee (http://www.nccrcg.org/RSSMAC)
} 
family-focused clinical services and population-based services. Objectives of genetic services encompass genetic testing, diagnosis, counseling, follow-up, support services to extended families, education, and coordination of health surveillance.

This report summarizes the data gathering and analysis of the Regional Support Services Model Workgroup (WG) and Advisory Committee (AC), established by NCC to outline structures for regional genetic services support centers that improve access to clinical genetic services. The WG and AC recognized that the use of recent technologies, especially in healthcare informatics and telehealth, might increase access and quality of service delivery and thereby address unmet needs for genetic services. Recommendations to address some systemic barriers, including the variability and number of health insurance plans and the variability of their essential genetic services, lack of mandatory coverage for certain important services, and low payment for cognitive as opposed to procedural work, were beyond the scope of this project. Rather, the WG was asked to consider ways in which various service model structures might improve access in the face of these barriers. Other barriers, such as licensure across state lines and an inadequate focus on the mental health domain, were considered to be within the broad scope of this review. Redefinition of the roles of primary care providers, subspecialists without genetics training, and genetic counselors were also considered as a method to improve quality and access to genetic services.

\section{MATERIALS AND METHODS}

The WG conducted a literature review seeking published data and information on genetic service delivery models ${ }^{1-12}$ using the following key words: genetic service delivery, regional models, public health genetics, regional health systems, healthcare services delivery. The WG then focused on two sets of information: need for genetic services and the infrastructure needed to deliver those services. First, NCC and the National Genetics Education and Consumer Network (NGECN) conducted an assessment of the need for genetic services. This assessment began with stakeholder listening sessions from January through July 2015 for stakeholders not engaged in the current regional genetics collaborative system. Stakeholders were identified through open solicitation of American College of Medical Genetics and Genomics (ACMG) members, Family Voices members, American Academy of Pediatrics (AAP) Genetics workgroup, regional genetics collaboratives, public health genetics professionals, and consumer organizations. The in-person and telephonebased sessions asked at least the following four broad questions, but were otherwise unstructured and open-ended: (1) How do you define genetic services?, (2) What are existing gaps in genetic services?, (3) What are existing regional models that should be considered?, and (4) What key elements should a regional genetic support service center model contain? The sessions offered insight into how genetics professionals, consumers, public health, and primary care providers perceived the current gaps in services. These sessions, with more than 250 participants, formed the basis for the NCC and NGECN-led national needs assessment surveys conducted in late 2015 with consumers, genetics professionals, public health, and primary care professionals (NCC provider survey, fall 2015, 924 respondents; NGECN consumer survey, fall 2015, 1355 respondents). Data from the surveys were provided to the $\mathrm{WG}$ and $\mathrm{AC}^{13}$ and were analyzed to identify priorities for future regional genetic services support centers. Based on the priorities identified from the needs assessment surveys, the WG developed an initial set of 25 components to be included in future regional genetics services support centers. By combining similar components, this list was refined to 15 priority needs that were grouped into 6 categories (Table 1 ).

Next, the WG reviewed existing national and regional centers supporting individuals and their families with genetic and other conditions. Thirty-five service centers providing regional care were identified via the listening sessions, along with $\mathrm{AC}$ and WG member recommendations. Ultimately 14 centers were prioritized for review based on a survey sent to the WG and AC; they were then reviewed using a center review template. The service centers chosen represented diverse programs serving individuals and their families with genetic and other conditions and providing services at the state, regional, and/or national levels. See Table 2 for reviewed centers, and Table 3 for the center review template.

The WG and AC included center characteristics as components of model systems based on information received from the centers; for example, no center provided onsite mental health services, so this characteristic was not included as a characteristic as models were proposed. However, characteristics considered as high priority in the needs assessment, such as inclusion of families in decision-making roles, were included in final recommendations even if not identified in reviews of the 14 centers. As a result of this process, the WG and AC identified eight models. These models sought to identify possible organizational structures and overall purposes of these structures. Each model's advantages and disadvantages were identified by the WG and $\mathrm{AC}$. The AC provided the WG oversight and reviewed the products of the WG. Together, the AC and WG proposed a series of recommendations, based on considerations of local, regional, and national needs, to build a system to improve access to genetic services.

\section{RESULTS}

Review of the 14 centers showed great variability in mission, resulting in highly individualized organizational structure, budget, source of funding, populations served, services provided, staffing, and ability to measure impact. Key themes across all reviewed centers included the following: a regional collaborative structure with a central coordinating office can facilitate sharing of resources; technical assistance (e.g., telehealth) can expand the availability of health care to underserved populations; and workforce issues are real, which limits the expected role of the specialist. The eight models 
Table 1 Identified priorities based on national needs assessments and potential strategies to address them (not ranked; listed alphabetically) ${ }^{1}$

\section{Data collection}

- Facilitate the acquisition of new knowledge

- Utilize appropriate existing data sources

Education and training on genetics for non-genetic providers

- Provide access to appropriate genetic resources

- Facilitate ongoing relationships between nongenetics and genetics providers

- Provide genetic consults for non-genetic providers (more like ECHO and less like a direct service)

- Increase public education

- Target education at points of care, e.g., federally qualified health centers (FQHCs) and other large providers that don't focus on genetics

\section{Efficient practice}

- Enhance effectiveness of workforce through telegenetics and other service delivery models

- Promote and facilitate entry into the field (workforce)

\section{Formal relationships with state public health, healthcare institutions, and university centers}

- Develop contract and/or partnerships agreements for specific services, e.g., provide telemedicine support in your institution, report specified data, provide referrals to specialists

- Formalize relationships between institutions, health departments

- Facilitate partnerships to bring resources to the table

- Provide technical assistance to states with no genetics beyond newborn screening (NBS) to internalize the importance of genetics in public health at a state level, e.g., cancer

- Work actively with Medicaid

- Demonstrate a minimum set of core partnerships (e.g., Medicaid, Department of Health, university centers, Title V)

\section{Practice support}

- Support authorization and reimbursement (including billing and insurance)

- Support contractual services

- Support medical home model

- Connect with or provide access to national level expertise

\section{Promotion of family engagement}

- Facilitate finding and providing ongoing care to underserved families and groups (broadly defined; underserved may include initial services)

- Detect health disparities

- Consider health equity

- Identify relevant resources and supports including where to find providers with knowledge of the condition

- Enhance availability of social and emotional support

- Improve care coordination

- Provide information to consumers on tests and treatments for their conditions

- Assure information is delivered at the right time, as part of a standard of care and is provided where people are receiving care

\section{Table 2 Reviewed regional centers}

California Genetic Disease Screening Program (GDSP) Regional Newborn Screening Model Cystic Fibrosis Centers/Cystic Fibrosis Foundation

East Anglia Regional Genetics Services (a unit of United Kingdom Clinical Genetic Services)

Geisinger Health System

Hawaii Department of Health Genomics Section/Hawaii Community Genetics

Hemophilia (Thrombosis) Treatment Centers: National Hemophilia Program

Muscular Dystrophy Association (MDA) Clinics

National Coordinating Center (NCC) and the seven Regional Genetic Service Collaboratives (RC)

National Down Syndrome Society

State of Alaska Genetics and Birth Defects Program

State of Alaska Metabolic Clinic

Seattle Children's Hospital

Veteran's Administration Genomic Medicine Service (Telegenomics Program)

Washington State Department of Health: Regional Genetics Clinics 
Table 3 Template elements

\begin{tabular}{|c|c|}
\hline Item & Description \\
\hline Mission & $\begin{array}{l}\text { Includes specific services that the } \\
\text { agency engages in to address the } \\
\text { mission }\end{array}$ \\
\hline Organizational structure & $\begin{array}{l}\text { How is the organization organized } \\
\text { internally (e.g., hub and spoke } \\
\text { model)? Nonprofit, for profit, } \\
\text { government agency? Number and } \\
\text { locations of regional centers }\end{array}$ \\
\hline Patients/populations served & $\begin{array}{l}\text { Indicate population the center is } \\
\text { attempting to reach (e.g., all } \\
\text { individuals with Down Syndrome in a } \\
\text { state) and the actual number served } \\
\text { (within the context of a time frame) }\end{array}$ \\
\hline Services provided & $\begin{array}{l}\text { Direct care, enabling, infrastructure } \\
\text { building, population-based, etc. }\end{array}$ \\
\hline Funding & $\begin{array}{l}\text { What is the source of funding and the } \\
\text { amount of funding over a specified } \\
\text { period of time? Include mechanism } \\
\text { for how funds are distributed (e.g., } \\
\text { accreditation, reimbursement, satellite } \\
\text { offices) and percentage from all } \\
\text { funding sources; if there is a central } \\
\text { coordinating body, how is it funded? } \\
\text { (excluding physician fees unless the } \\
\text { central coordinating body is the } \\
\text { recipient or payer of such fees); } \\
\text { include budget when available (if not } \\
\text { available, include \% of budget used } \\
\text { for services being described) }\end{array}$ \\
\hline \multicolumn{2}{|l|}{$\begin{array}{l}\text { How do they reach underserved } \\
\text { populations (if they do)? }\end{array}$} \\
\hline \multicolumn{2}{|l|}{$\begin{array}{l}\text { Cross-state line challenges } \\
\text { (licensure, etc.) }\end{array}$} \\
\hline Impact & $\begin{array}{l}\text { How do you measure the impact and/ } \\
\text { or success of your services? Please } \\
\text { share any data you have on impact or } \\
\text { outcomes }\end{array}$ \\
\hline \multicolumn{2}{|l|}{ Mental health services provided } \\
\hline Resources & $\begin{array}{l}\text { Is there a set of resources that the } \\
\text { central coordinating body makes } \\
\text { available to satellite centers? If so, } \\
\text { what are these resources? }\end{array}$ \\
\hline $\begin{array}{l}\text { How does an entity (clinic, } \\
\text { provider, etc) become a part of the } \\
\text { system? }\end{array}$ & Application, evaluation process, etc. \\
\hline Staffing & $\begin{array}{l}\text { Are there staffing issues, who is a part } \\
\text { of the team? }\end{array}$ \\
\hline Telephone consultation & $\begin{array}{l}\text { Telemedicine technology (current or } \\
\text { planned usage) }\end{array}$ \\
\hline $\begin{array}{l}\text { Please list any gaps/barriers that } \\
\text { you (as the reviewer) have } \\
\text { identified through the review } \\
\text { process }\end{array}$ & \\
\hline
\end{tabular}

identified by the WG and AC are shown in Table 4; each model emphasized one of the following priorities: regionalization with state teams, local clinical support, education and technical assistance, patient engagement, public health, quality improvement, regional clinical support, and data collection. Focus on these individual priorities allowed the WG and AC to assess the feasibility of recommending a center structure that utilized all available resources for a welldefined but single purpose. The advantages and disadvantages of the different models were compiled by the WG and AC and are shown in Table 5.

\section{DISCUSSION}

Following review, the AC and WG proposed adoption of a hybrid model combining components of models 1, 2, and 3 . Each of these three models utilized a regional infrastructure.
Model 1 built upon the regional infrastructure, including public health and health-care professionals and families, to develop a team of stakeholders and implement projects to improve access to genetic services. Model 2 promoted efficient practice within genetic centers: technical assistance (TA) for telegenetics, TA for authorization of genetic testing and other genetic services, TA for genetic counselor licensure and billing, and other activities as identified through interaction with genetics providers. Model 3 emphasized aggressive and targeted support of nongenetics providers through promotion of their relationships with genetic centers, provision of pointof-care decision support tools, and development of other tools to enhance the level of care that can be delivered in conjunction with but outside of the genetics center itself. The hybrid model included all of these elements, although the WG and AC recognized that some issues might remain unaddressed.

The WG also identified two overarching principles that should guide the development of future genetic services support centers: (1) family engagement, including inclusion of family advocates in leadership roles, is fundamental to future genetic services support centers; and (2) the goals and activities of regional genetic services support centers should be similar enough to allow identification of meaningful national outcome measures and quality of genetic services. However, these national activities and goals should not preclude regional-level innovation. In addition to the overarching principles noted above, the WG and AC recommended that four key components be included in future regional genetics support service centers. These components were identified based on center reviews as well as the experience of WG and AC members in delivery of genetic services and in public health genetics:

1. A regionalized structure. This structure is envisioned as collaborative, with interventions at the delivery system level. This structure permits attention to geographic and demographic factors that vary across the United States (e.g., northeastern United States versus western United States, including Hawaii and Alaska). Such attention can increase access to genetic services by permitting the design of interventions that make sense in some regions but not in others. This recommendation was based on reviews of other regional infrastructures (e.g., cystic fibrosis centers); it leverages the success of the current regional infrastructure as a framework for bringing together genetics stakeholders and establishing relationships among diverse partners.

2. Coordination through a central coordinating body. Central coordination, through a collaborative process, ensures that the support centers adopt national goals and implement them to permit national data collection demonstrating national outcomes.

3. Integration within the health-care delivery system. This is a requirement for meaningful impact on access to genetic services. Providers and consumers agreed that substantial 


\title{
Table 4 Eight regional models
}

\begin{abstract}
Model 1: Regional genetic service resource network. A regional infrastructure with a central coordinating body. Regions would work with states, providers, and consumers to develop a team of stakeholders and implement projects that improve access to genetic service. Goals and priorities for these projects would be congruent with guidance provided by the Genetic Services Branch (GSB) and Health Resources and Services Administration (HRSA) Specific project deliverables would be consistent with regional needs. This model could utilize elements of the below models as project deliverables.
\end{abstract}

Model 2: Regional clinical support centers. Using a regional infrastructure, the focus would be on clinical providers, public health genetics, or both with activities limited to supporting clinical services through technical assistance (e.g., telemedicine), clinical support (education), care coordination, evaluation, and workforce capacity.

Model 3: Regional genetics education and technical assistance centers. A regional infrastructure would focus on both clinical and public health providers. Primary focus is on development of materials and/or education similar to the ECHO model, and public health and non-genetics provider education timed to the right time and place.

Model 4: Regional patient engagement centers. Regionalized centers would pursue activities focused on consumers. Primary partners may be Genetic Alliance, public health departments, or both. Activities would be limited to administration, patient engagement including care coordination, and education

Model 5: Public health model. This model could be administered by a central coordinating body, only regional centers, or both. This would address public health concerns (e.g., policy development), and funding would support a state genetics coordinator in each state. The coordinator would work with individuals in genetic and chronic disease offices through Title $\mathrm{V}$. The main role would be to build a tight integration with the public health workforce that would demonstrate and eventually address need.

Model 6: Quality improvement model. A regional infrastructure with a centralized coordinating body would engage in activities focused on a plan to develop, implement, and evaluate formal quality improvement processes to improve access. This could be a single project across the country. A modification could be a national quality improvement (QI) focused project, with a proportion of funds at the Regional Collaborative Group (RC) level supporting RC-specific projects.

Model 7: Regional clinical support network. Regions provide clinical services via local or state clinics receiving funds from regional centers to meet specific and unique needs as identified by the local/state centers. A national coordinating body would coordinate the regions, and specific goals and objectives would be established for each local/state clinic at the start of each funding period.

Model 8: Genetic service data centers. This model could utilize a regional infrastructure, where the central coordinating body would work with HRSA to determine the data of interest and possible national data sources. Regional centers would work with clinical entities, consumers, and states to collect data related to access to genetic services, focusing on where patients are, their demographic and clinical characteristics, when and where they receive services, and gaps in service.

\section{Recommended hybrid model:}

Genetic services support model: This model would have a primary focus on promotion of efficient practice within genetic centers (technical assistance [TA] for telegenetics, TA for authorization of genetic testing and other genetic services, TA for genetic counselor licensure and billing; other activities as identified through interaction with genetics providers), and aggressive and targeted support of nongenetics providers through promotion of other tools to enhance the level of care that can be delivered in conjunction with, but outside of, the genetics center itself.

day-to-day systemic challenges at all levels (provider, consumer, insurer, and clinic) prevent identification of patients needing services, referral, authorization, and timely provision of services. Active engagement with clinicians in their daily patient care activities (e.g., technical assistance in the development of telegenetics, design and monitoring of quality improvement projects, assistance in strengthening relationships between genetics providers and primary care providers) is critical if resource centers are to impact access.

4. Coordination/collaboration with state public health departments. States have a key role in identification, assessment, policy development, and assurance for individuals and populations in need of genetic services. Therefore, they must function with the health-care delivery system and consumers as all grapple with dayto-day systemic challenges of providing care. As examples of effective state engagement in genetic services, Hawaii and Washington public health departments have had a central role in reaching underserved populations through support of genetics outreach services and genetics professional recruitment.

The relationship of future regional genetics support service centers to state public health departments should be regionspecific, taking into account the current commitment of individual states to genetic services, since there is wide variability in state fiscal and infrastructure commitment to genetics. Engaging all state public health departments within future regional service support centers will provide twofold benefit: where a state's commitment is limited, future support centers' activities should emphasize information exchange, partnerships and mentoring opportunities, and policy development for genetic conditions of public health impact. States that have invested significant resources in genetics have an integral role in regional centers. Such states demonstrate what 


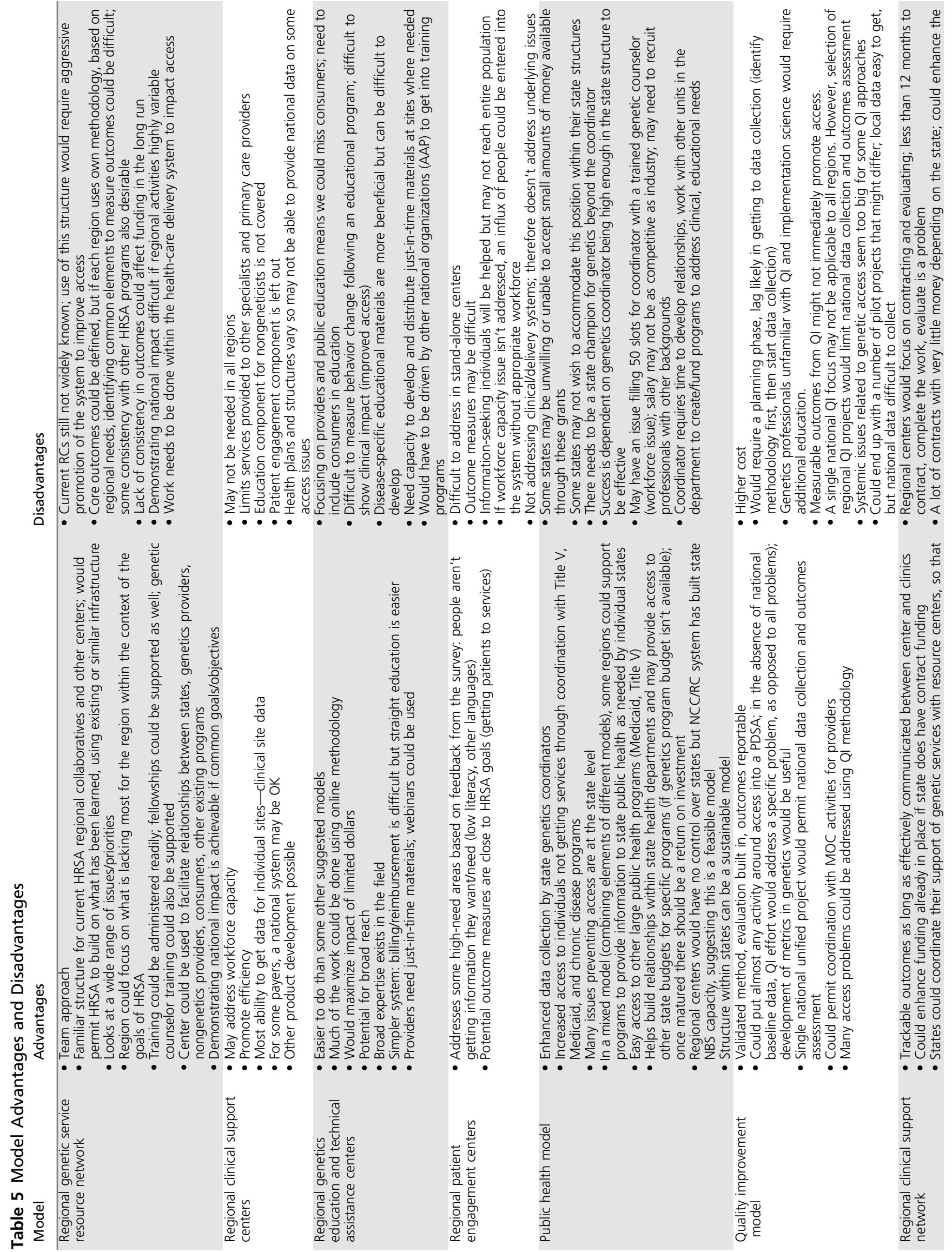




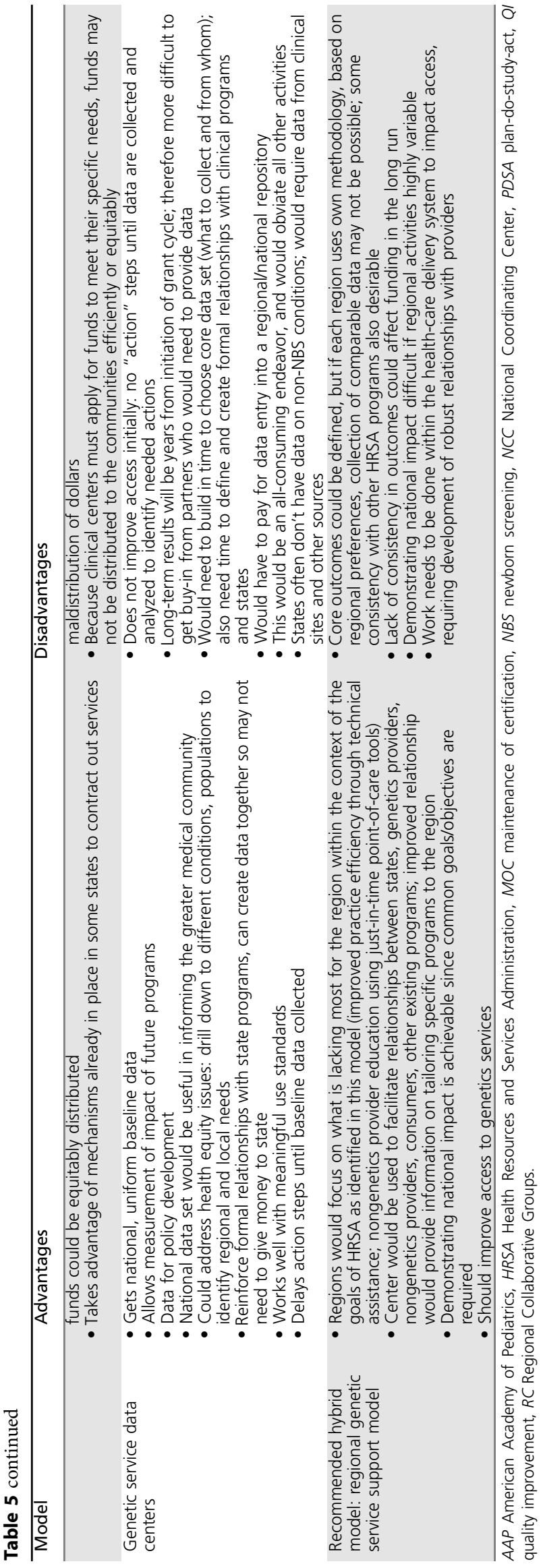

an expanded state engagement in genetics produces, and they can mentor other states as they enhance their genetics programs. HRSA, through MCHB and GSB, could model support for genetic services via prioritizing genetics objectives throughout MCHB programs and enhancing the role of genetic services in broader access to service programs, such as Title V.

The WG and AC recognized multiple remaining critical gaps in providing access to genetic services that extend in time, scope, and financial reach beyond what likely future regional genetic service support centers could address. These gaps fall within two general areas: workforce and data. Workforce gaps include provision of nongenetics provider education; support for increasing the number of physician geneticists, genetic counselors, and other highly specialized providers for treatment of genetic conditions (e.g., dietitians for metabolic conditions); and provision of mental health services for those impacted by genetic conditions. Genetics data gaps are systemic, in that there currently is no collection of robust national and regional data on access to genetic services. The WG and AC recommended that GSB and HRSA begin to address these gaps through internal resources and collaborations with national professional organizations.

\section{ACKNOWLEDGEMENTS}

This project was supported by the HRSA of the US Department of Health and Human Services (HHS) under Cooperative Agreement U22MC24100, NCC for the Regional Genetic Service Collaboratives, \$1,599,999 (6/15-5/17) awarded to the American College of Medical Genetics and Genomics.

\section{DISCLOSURE}

The authors declare no conflicts of interest.

Publisher's note Springer Nature remains neutral with regard to jurisdictional claims in published maps and institutional affiliations.

\section{REFERENCES}

1. Cragun D, Lewis C, Camperlengo L, Pal T. Hereditary cancer: example of a public health approach to ensure population health benefits of genetic medicine. Healthcare. 2016;4:6.

2. Doyle DL. Genetic service delivery: the current system and its strengths and challenges. Innovations in service delivery in the age of genomics: workshop summary. Washington, DC: Institute of Medicine (US) Roundtable on Translating Genomic-Based Research for Health; 2009.

3. Etchegary $\mathrm{H}$. Healthcare experiences of families affected by Huntington disease: need for improved care. Chronic IIIn. 2011;7:225-238.

4. Kaye C. Genetic service delivery: infrastructure, assessment and information. Public Health Genomics. 2012;15:164-171.

5. Kaye Cl, Livingston J, Canfield MA, Mann MY, Lloyd-Puryear MA, Therrell BL. Assuring clinical genetic services for newborns identified through U.S. newborn screening programs. Genet Med. 2007;9:518-527.

6. Khoury MJ, Gwinn M, Bowen MS, Dotson WD. Beyond base pairs to bedside: a population perspective on how genomics can improve health. Am J Public Health. 2012;102:34-37.

7. Landis BJ, Ware SM. The current landscape of genetic testing in cardiovascular malformations: opportunities and challenges. Front Cardiovasc Med. 2016;3:22.

8. Lin-Fu JS, Lloyd-Puryear M. Access to genetic services in the United States: a challenge to genetics in public health. In: Khoury MJ (ed.) Genetics and 
public health in the 21st century. New York: Oxford University Press; 2000. p. 273-290

9. Marcus PM, Pashayan N, Church TR, et al. Population-based precision cancer screening: a symposium on evidence, epidemiology, and next steps. Cancer Epidemiol Biomarkers Prev. 2016;25:1449-1455.

10. Shieh Y, Eklund M, Sawaya GF, Black WC, Kramer BS, Esserman LJ. Population-based screening for cancer: hope and hype. Nat Rev Clin Oncol. 2016;13:550-565.

11. Shields AE, Burke W, Levy DE. Differential use of available genetic tests among primary care physicians in the United States: results of a national survey. Genet Med. 2008;10:404-414.

12. Trepanier AM, Allain DC. Models of service delivery for cancer genetic risk assessment and counseling. J Genet Couns. 2013;23: 239-253.

13. Maiese DR, Keehn A, Lyon $M$, et al. Current conditions in medical genetics practice. Genet Med. 2019;21:1874-1877.
Open Access This article is licensed under a Creative Commons

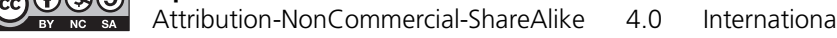
License, which permits any non-commercial use, sharing, adaptation, distribution and reproduction in any medium or format, as long as you give appropriate credit to the original author(s) and the source, provide a link to the Creative Commons license, and indicate if changes were made. If you remix, transform, or build upon this article or a part thereof, you must distribute your contributions under the same license as the original. The images or other third party material in this article are included in the article's Creative Commons license, unless indicated otherwise in a credit line to the material. If material is not included in the article's Creative Commons license and your intended use is not permitted by statutory regulation or exceeds the permitted use, you will need to obtain permission directly from the copyright holder. To view a copy of this license, visit http://creativecommons.org/licenses/by-nc-sa/4.0/.

(c) The Author(s) 2019 